\title{
Dioscin Decreases Breast Cancer Stem-like Cell Proliferation via Cell Cycle Arrest by Modulating p38 Mitogen-activated Protein Kinase and AKT/mTOR Signaling Pathways
}

\author{
Chae Won Ock ${ }^{1,2}$, Gi Dae Kim² \\ ${ }^{1}$ College of Pharmacy, Natural Products Research Institute, Seoul National University, Seoul, ${ }^{2}$ Department of Food and \\ Nutrition, Kyungnam University, Changwon, Korea
}

\begin{abstract}
Dioscin (DS), a steroidal saponin, has been shown to have anti-cancer activity by exerting antioxidant effects and inducing apoptosis. However, the anti-cancer activity of DS in breast cancer-derived stem cells is still controversial. The purpose of this study was to evaluate the effects of DS on migration, invasion, and colony formation in MDA-MB-231 and MCF-7 cell lines and the mechanism by which it inhibits proliferation of breast cancer stem-like cells after inducing differentiation into breast cancer stem cells. DS treatment significantly reduced cellular migration, invasion, and colony formation in MDA-MB-231 and MCF-7 cells. During the differentiation process that induced manifestation of breast cancer stem-like cells, DS significantly inhibited mammosphere formation in a dose-dependent manner and increased the expression of p53 and p21 in breast cancer stem-like cells, reducing the expression of cdc2 and cyclin B1 in MDA-MB-231 cells and cyclin D, cyclin E, CDK4, and CDK2 in MCF-7 cells. Interestingly, DS treatment induced G2/M and G0/G1 cell cycle arrest in the MDA-MB-231 and MCF-7 cells, respectively. DS also increased the phosphorylation of p38 and decreased the expression levels of p-AKT and p-mTOR. These results suggest that DS regulates the p38 mitogen-activated protein kinase and AKT/mTOR signaling pathways to reduce the proliferation of breast cancer stem-like cells through cell cycle arrest. Therefore, these findings suggest that DS may serve as a potential treatment candidate targeting breast cancer stem cells.
\end{abstract}

Key Words Dioscin, Breast cancer, AKT/mTOR

\section{INTRODUCTION}

Breast cancer is one of the deadliest malignant adenocarcinomas in women, and breast cancer-related mortality is mostly caused by invasion and metastasis $[1,2]$. Triple-negative breast cancer (TNBC), lacking estrogen receptor $\alpha$, progesterone receptors, and HER2, has a high risk of recurrence and metastasis and a low survival rate after onset [3]. A recent study reported that TNBC cells had characteristics including metastasis, chemoresistance, and recurrence similar to breast cancer stem cells (BCSCs), which are breast-cancer initiating cells. Their therapeutic efficacy was reported in a pre-clinical study of TNBC targeting cancer stem cells (CSCs) [4]. CSCs have stem cell properties such as self-renewal and multi-lineage differentiation and can promote the mass formation of tumors including breast cancer [5]. CSCs, which are a subpopulation of tumor cells, are same cells as cancer stem-like cells [6]. In various types of breast cancer, BCSCs express specific markers such as CD44 ${ }^{+}$CD24-, epithelial-specific antigen, and CD326 (EpCAM), and have aldehyde dehydrogenase activity [7]. In particular, CD44 is a receptor for extracellular matrix hyaluronan, which acts together with the tyrosine kinase receptor as a surface marker of BCSCs and activates the signaling pathway related to the proliferation and colony formation of BCSCs. In contrast, the CD24 marker was identified as a glycoprotein on the surface of differentiated breast cancer cells [8].

Dandawate et al. [9] reported that various phytochemicals and their analogs could target CSCs by inhibiting signaling pathways responsible for self-renewal and differentiation of

Received August 30, 2021, Revised September 14, 2021, Accepted September 15, 2021

Correspondence to Gi Dae Kim, E-mail: gidaekim@kyungnam.ac.kr, https://orcid.org/0000-0002-8149-5361

Check for updates 
CSCs. The phosphatidylinositol-3-kinase (PI3K)/AKT and the mTOR signaling pathways play important roles in cancer cell growth, proliferation, motility, survival, and angiogenesis [10-12]. In chemotherapy, CSCs show multidrug resistance, leading to cancer recurrence and metastasis [13]. As the $\mathrm{PI} I \mathrm{~K} / \mathrm{AKT}$ signaling pathway can promote CSC activity [14], regulation of this pathway may provide a potential strategy for overcoming resistance to breast cancer therapy [15].

Many phytochemicals have been reported to show pharmacological efficacy and inhibit the pathogenesis of various diseases [16]. In particular, saponin, which is a triterpenoid or steroidal glycoside widely distributed in plants, marine organisms, and some bacteria, has a wide range of biological properties [17]. For instance, dioscin (DS), a steroidal glucoside saponin (Fig. 1A), has been used in traditional medicine for treating hypercholesterolemia, hyperglycemia, and diabetes [18-21]. DS has also been reported to inhibit cancer cell proliferation in a number of human cancer cells [22]. The anticancer activity of DS has been demonstrated in studies on the regulation of different cell signaling processes involved in the growth, differentiation, apoptosis, and progression of can- cer cells [23]. However, studies on anticancer activity of DS in BCSCs are still lacking. Furthermore, there are no reports on the anti-migrative ability of DSs in BCSCs, although DS was shown to inhibit migration and invasion via suppressing TGF- $\beta 1$-induced epithelial-mesenchymal transition in lung cancer cell lines (A549) [24]. The purpose of this study was to compare the effects of DS on migration, invasion, and colony formation in MDA-MB-231 and MCF-7 cells that are derived from TNBC and estrogen receptor positive luminal breast cancer, respectively. Further, its anticancer activity in breast cancer stem-like cells and underlying mechanisms were also explored.

\section{MATERIALS AND METHODS}

\section{Reagents}

DS was purchased from Sigma-Aldrich (St. Louis, MO, USA). The compound was dissolved in $100 \%$ dimethyl sulfoxide (DMSO). A $50 \mathrm{mmol} / \mathrm{L}$ stock solution of DS was prepared and stored as small aliquots at $-20^{\circ} \mathrm{C}$ until used. We purchased MTT, DMSO, gelatin, and horseradish peroxidase (HRP)-con-

A

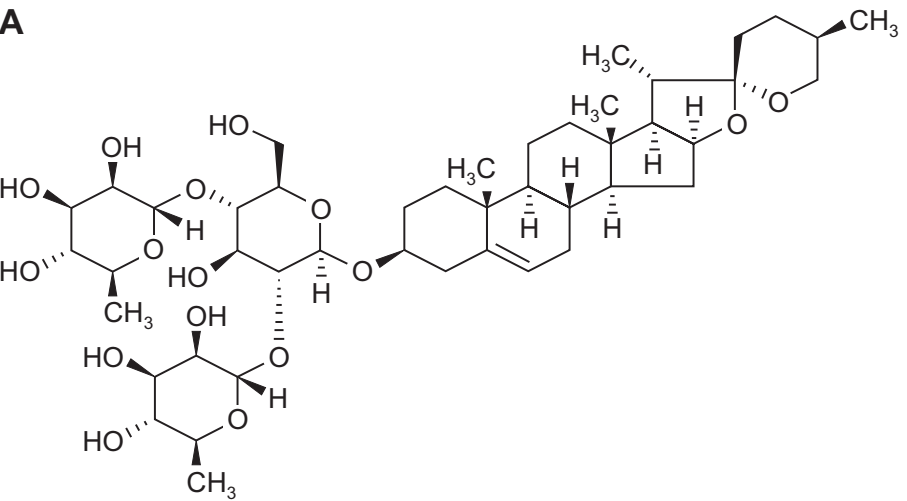

B

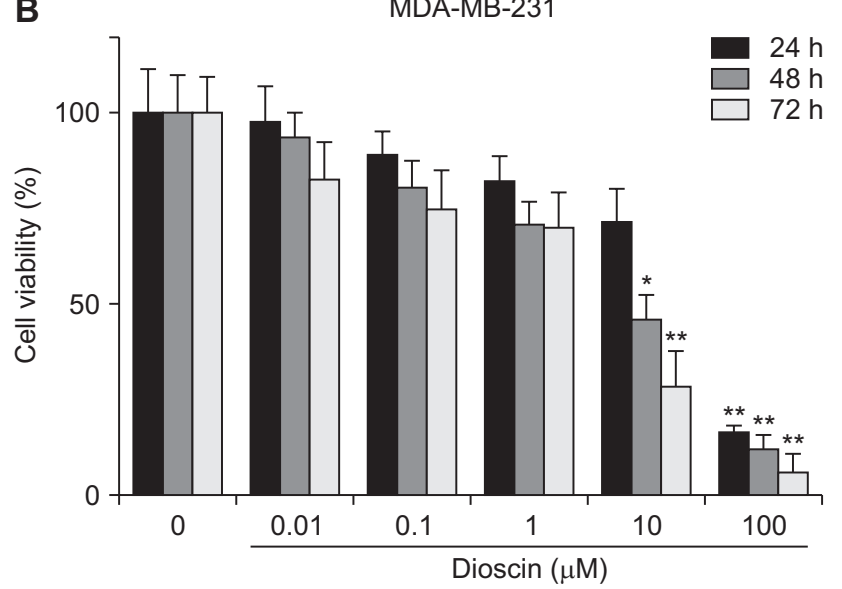

C

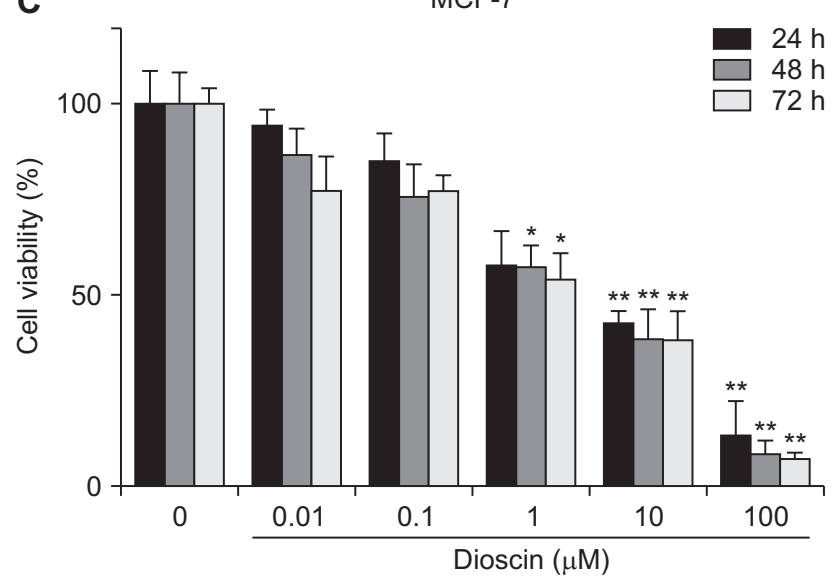

Figure 1. Effect of dioscin on the viability of human breast cancer cells. (A) Structure of dioscin. MDA-MB-231 (B) and MCF-7 (C) human breast cancer cells were incubated with selected concentrations of dioscin $(0$ to $100 \mu \mathrm{M})$ for 24 to 72 hours. The results indicated that dioscin significantly inhibited human breast cancer cell growth in concentration- and time-dependent manners compared to non-treated (control group) cells. The results are expressed as the mean $\pm \mathrm{SD}$ of at least three independent experiments. Statistical differences were analyzed with $S$ tudent's $t$-test $\left({ }^{*} P<0.05\right.$, ${ }^{* *} P$ $<0.01$ vs. controls). 
jugated anti-mouse and anti-rabbit antibodies from Sigma-Aldrich. Fluorescein isothiocyanate (FITC)-conjugated CD44 and phycoerythrin (PE)-conjugated CD24 antibodies were purchased from BD Biosciences (San Jose, CA, USA). The phospho-specific antibodies anti-p38, anti-AKT, anti-mTOR, and specific antibodies anti-p38, anti-AKT, anti-mTOR, and AKT inhibitor LY294002 were purchased from Cell Signaling Technology (Danvers, MA, USA). HRP-conjugated $\beta$-actin, OCT4, proliferation cell nuclear antigen (PCNA), p53, p21, cdc2, cyclin B1, CDK4, cyclin D, CDK2, and cyclin E antibodies were purchased from Santa Cruz Biotechnology (Dallas, TX, USA).

\section{Cell culture}

Human breast cancer cells (MDA-MB-231 and MCF-7) were obtained from the American Type Culture Collection (ATCC; Rockville, MD, USA). The cells were cultured in $5 \% \mathrm{CO}_{2}$ in a $37^{\circ} \mathrm{C}$ humidified atmosphere in Dulbecco's modified Eagle's media (DMEM) supplemented with 10\% FBS and 1\% antibiotics-antimycotics and maintained at $37^{\circ} \mathrm{C}$ and $5 \% \mathrm{CO}_{2}$. The cells were passaged every 3 to 4 days.

\section{Cell viability assay}

DS cytotoxicity was assessed using the MTT assay. Cells were seeded in 96-well plates. After culturing overnight, the primary culture medium was removed, and fresh medium containing six different concentrations of DS $(0,0.01,0.1,1$, 10 , and $100 \mu \mathrm{M}$ ) was added for 24 to 72 hours. Then, $20 \mu \mathrm{L}$ of $5 \mathrm{mg} / \mathrm{mL}$ MTT in PBS was added to each well and incubated for 4 hours. Next, the media was removed and $100 \mu \mathrm{L}$ of DMSO was added to each well to stop the reaction. Cell viability was detected by measuring the optical density at 570 $\mathrm{nm}$ with a Synergy HTX plate reader (Bio-Tek Instruments, Inc., Winooski, VT, USA) and the Gen5 program.

\section{Scratch wound-healing assay}

A total of $4 \times 10^{5}$ cells were seeded into six-well plates and cultured for 24 hours, then an artificial wound was made with a P20 pipette tip in each well. The cells were washed three times with culture medium and fresh medium supplemented with DS (0 to $10 \mu \mathrm{M})$ was added. Images were captured at different time points (24 to 48 hours) under an inverted microscope equipped with a camera. The wound gap distance was quantitatively determined with ImageJ software (National Institutes of Health, Bethesda, MD, USA) and closure was determined as follows: Closure $(\%)=$ migrated cell surface area/total surface area $\times 100$.

\section{Invasion assay}

The cell invasion assay was performed using six-well dishes containing Transwell inserts with $8-\mu \mathrm{m}$ polycarbonate membranes (Corning Life Sciences, Tewksbury, MA, USA). Cells $\left(3 \times 10^{5}\right.$ cells $\left./ \mathrm{mL}\right)$ in $1.5 \mathrm{~mL}$ of serum-free DMEM/F12 medium were plated in the upper chamber (BD BioCoat ${ }^{\mathrm{TM}}$
Matrige $^{\mathrm{TM}}$ Invasion Chamber, Corning), while DMEM medium with $10 \%$ FBS was added to the lower chamber. In both the control and treatment groups, after 48 hours at $37^{\circ} \mathrm{C}$ and $5 \%$ $\mathrm{CO}_{2}$, the non-invading cells were removed from the upper chamber with a cotton swab. The invading cells were fixed in $4 \%$ paraformaldehyde for 30 minutes and stained with $0.5 \%$ crystal violet solution for 30 minutes, and the number of invasive cells in microscopic fields was counted.

\section{Colony formation assay}

Cells were seeded in triplicate at a density of 800 cells/well in six-well flat-bottom plates with $2 \mathrm{~mL}$ of DMEM containing $10 \%$ FBS. The cells were incubated with or without DS treatment for 48 hours and then cultured for 10 days at $37^{\circ} \mathrm{C}$ in a $5 \% \mathrm{CO}_{2}$ incubator. The cell colonies were fixed in methanol and stained with crystal violet. Images were captured under an inverted microscope equipped with a camera. The number of colonies that contained $>50$ cells was counted under a microscope. The number of colonies was quantitatively determined with ImageJ software.

\section{Mammosphere culture}

For mammosphere formation, MDA-MB-231 and MCF7 single-cell suspensions were plated at the density of $5 \times$ $10^{4}$ cells/well using the Mammocult ${ }^{\mathrm{TM}}$ Human Medium Kit (Stemcell Technologies, Vancouver, BC, Canada). The cells were seeded into Ultra-Low attachment 6 -well plates at $37^{\circ} \mathrm{C}$ and $5 \% \mathrm{CO}_{2}$. After seven days in culture, the primary mammospheres were gathered by gentle centrifugation. Then, the cells were re-plated to secondary and tertiary mammospheres [25].

\section{Cell surface markers measured by flow cytometry analysis}

Tertiary mammospheres from the MDA-MB-231 and MCF-7 cells were trypsinized to generate single cells. The recommended concentration of human CD44-FITC and CD24PE antibodies (BD Biosciences, San Diego, CA, USA) were added to the cell suspensions and the cells were incubated at room temperature in the dark for 30 minutes. Then, the cells were washed with PBS and analyzed using the FACSCalibur flow cytometer (BD Biosciences, San Diego, CA, USA) [26].

\section{Cell cycle analysis}

Cells were seeded in $100 \mathrm{~mm}$ diameter culture dishes and incubated for 24 hours, then treated with DS $(0,2.5,5$, and 10 $\mu \mathrm{M})$ for 24 hours. The cells were collected using trypsin-EDTA and fixed with $70 \%$ cold ethanol overnight at $-20^{\circ} \mathrm{C}$. The fixed cells were centrifuged $4^{\circ} \mathrm{C}$ at $5,000 \mathrm{rpm}$ for 5 minutes and washed with cold PBS, then incubated at $37^{\circ} \mathrm{C}$ for 30 minutes with $50 \mu \mathrm{g} / \mathrm{mL}$ of RNase A. The cells were stained with $50 \mu \mathrm{g} / \mathrm{mL}$ of propidium iodide $(\mathrm{PI})$ at $37^{\circ} \mathrm{C}$ for 15 to 30 minutes in the dark. The DNA content of the stained cells was analyzed using CellQuest Software and a FACS Vantage SE 
flow cytometer (BD Biosciences, San Diego, CA, USA).

\section{Western blot analysis}

The cells were treated with DS $(0,2.5,5$, and $10 \mu \mathrm{M})$ for 24 hours and lysed in PRO-PREP protein extraction solution containing phosphatase and protease inhibitors (Roche Diagnostics $\mathrm{GmbH}$, Mannheim, Germany) for 30 minutes at $4^{\circ} \mathrm{C}$.
Then, they were centrifuged at $4^{\circ} \mathrm{C}$ at $13,000 \mathrm{rpm}$ for $30 \mathrm{~min}$ utes. The whole protein samples $(30 \mu \mathrm{g})$ were separated on $8 \%$ to $10 \%$ SDS PAGE and transferred onto polyvinylidene fluoride membranes polyvinylidene fluoride membranes (Bio-Rad Laboratories, Inc., Hercules, CA, USA). The membranes were blocked with 5\% BSA (AMRESCO, Cleveland, $\mathrm{OH}, \mathrm{USA}$ ) and in TBS with $0.1 \%$ Tween 20 (TBS-T) for one

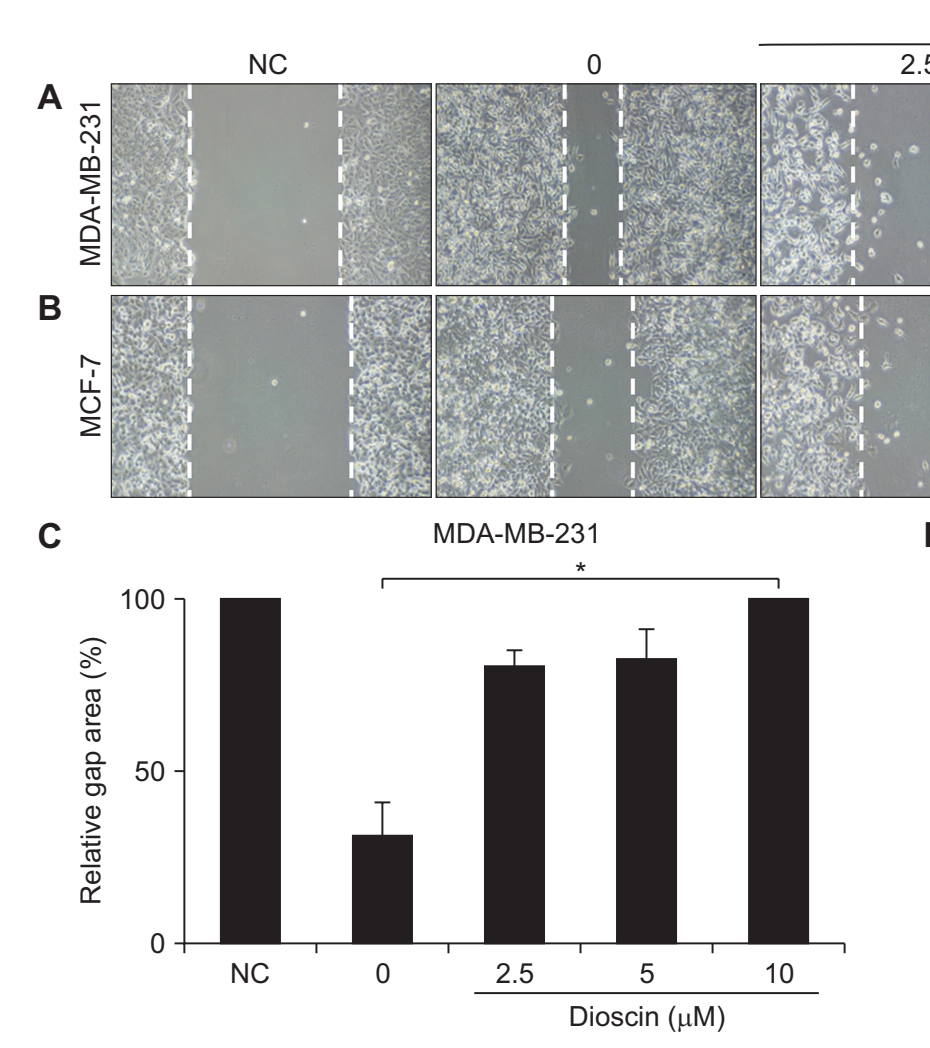

Dioscin $(\mu \mathrm{M})$

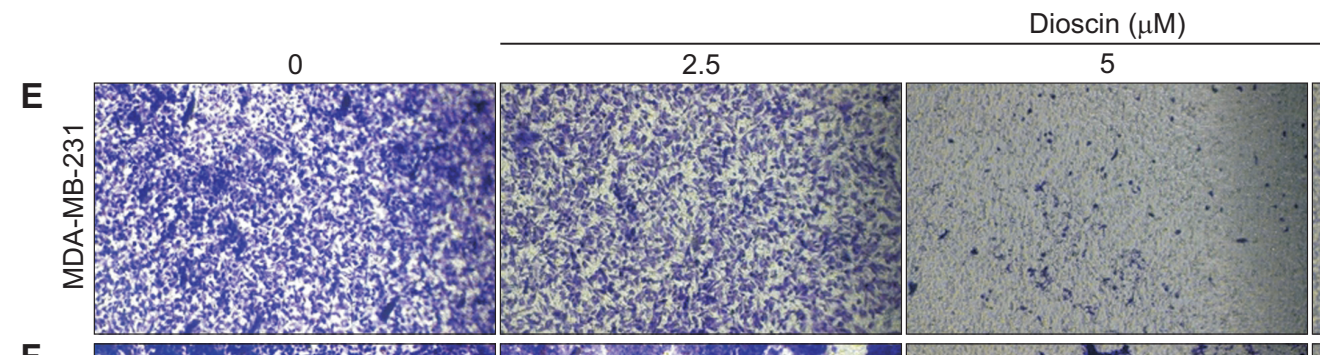

D

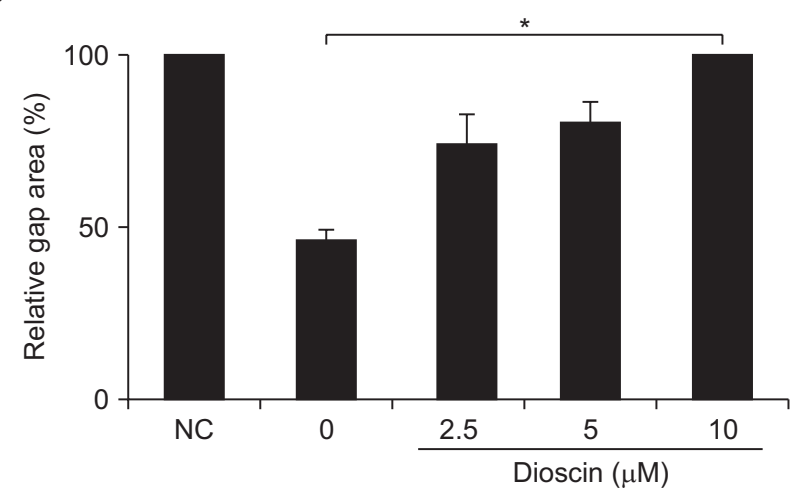

$\mathbf{F}$

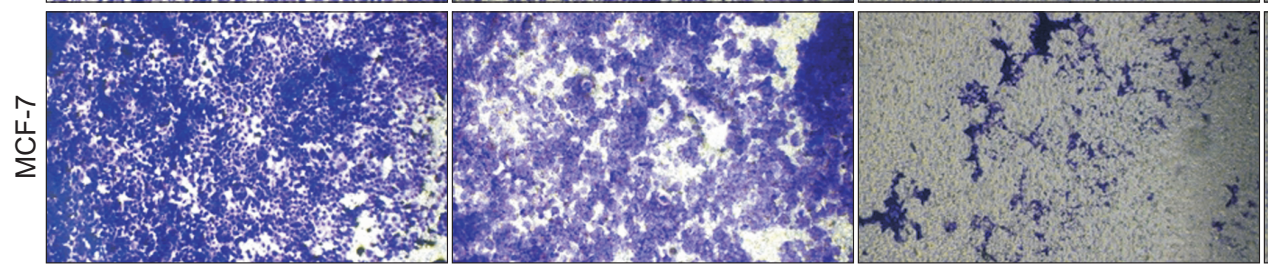

Figure 2. Effect of dioscin on cell migration, invasion, and colony formation in breast cancer cells. (A, B) Effect of dioscin on the migration of breast cancer cells. The cells were grown to confluence in 6-well plates, scratch-wounded, and treated with the indicated concentrations of dioscin. Magnification, $\times 100$. (C, D) Quantification of data shown in A and B. (E, F) Transwell assays were performed to determine the cell migration (without Matrigel) and invasion (with Matrigel) of the breast cancer cells exposed to dioscin. Magnification, $\times 100$. (G, H) Quantification of data shown in $E$ and $F$. $(\mathrm{I}, \mathrm{J})$ Effect of dioscin on the colony formation of breast cancer cells. The cancer cells were incubated in six-well plates and treated with dioscin. (K, L) Quantification of data shown in I and J. Magnification, $\times 100$. NC, negative control. The values represent the mean $\pm \mathrm{SD} ;{ }^{*} P<0.05,{ }^{* *} P<0.01$, ${ }^{* * *} P<$ 0.001 compared to the controls. 
G

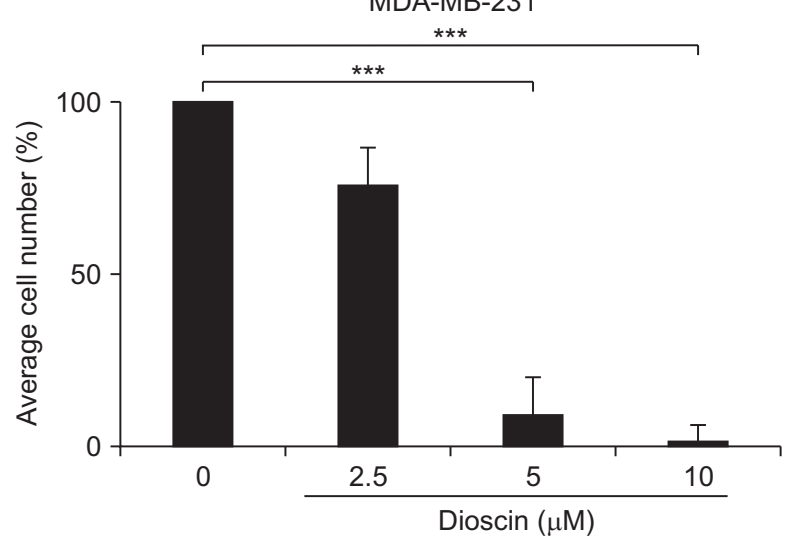

H

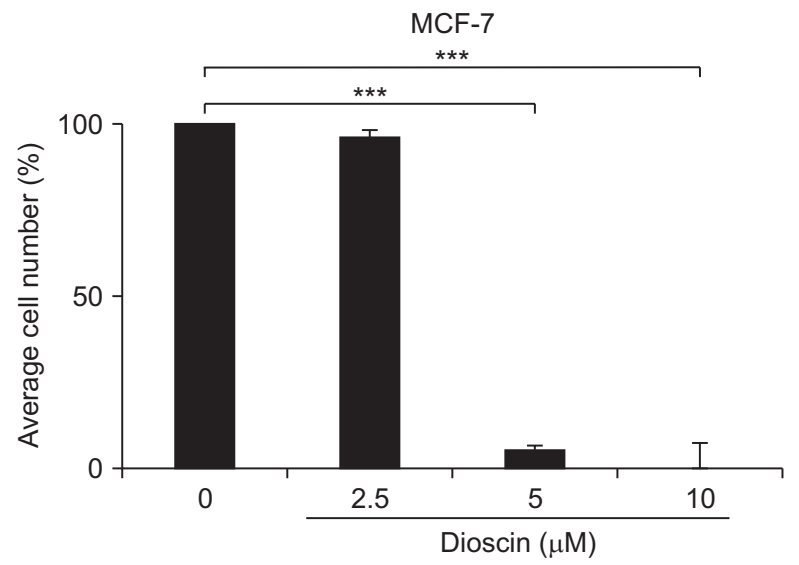

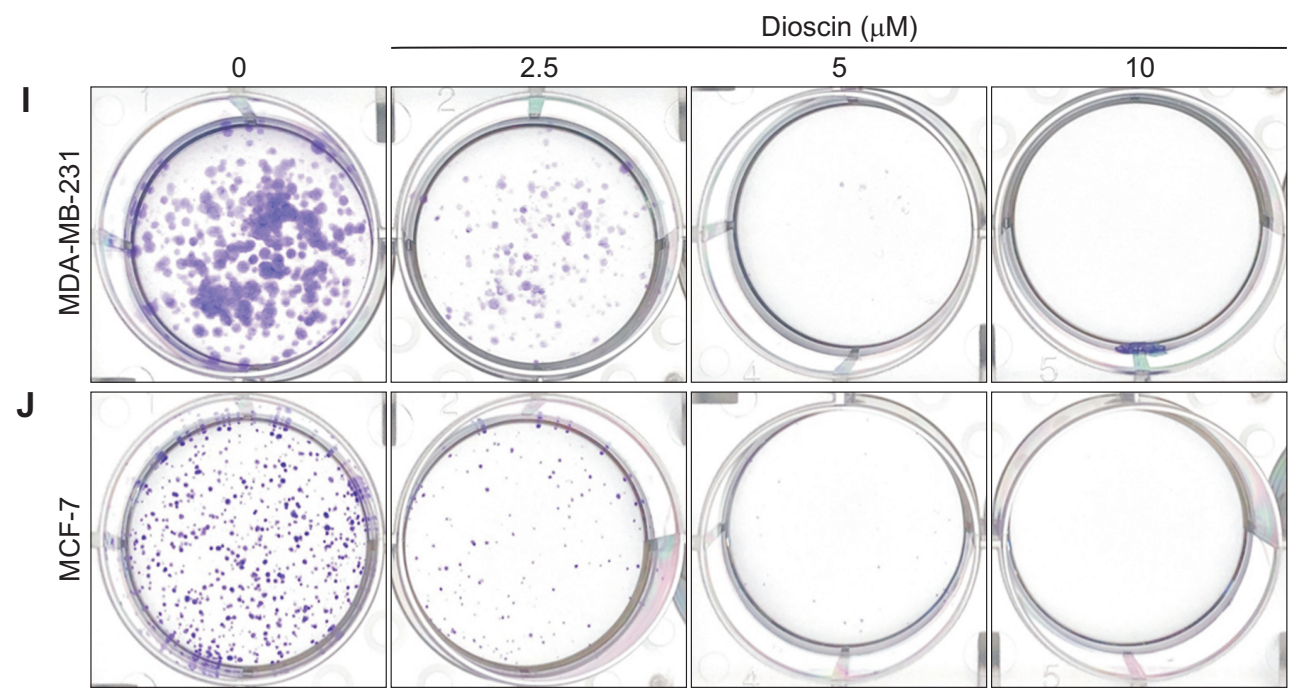

K

MDA-MB-231

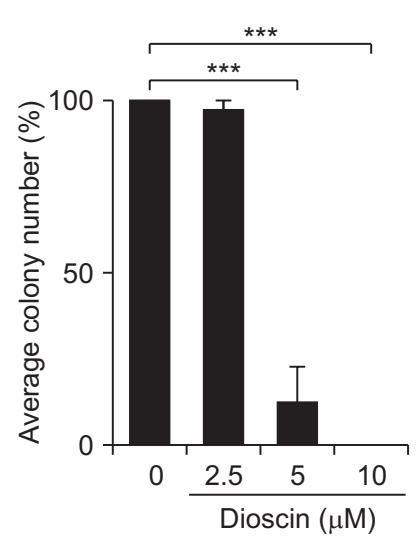

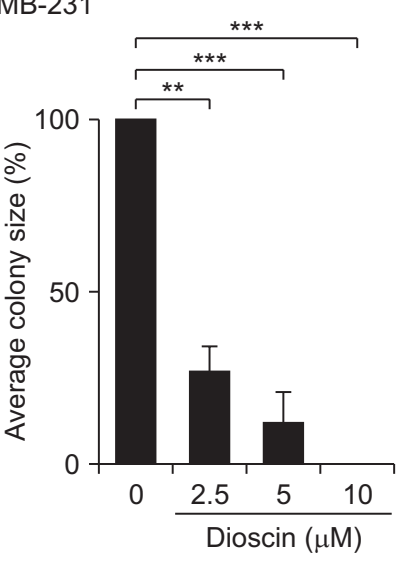

$\mathbf{L}$

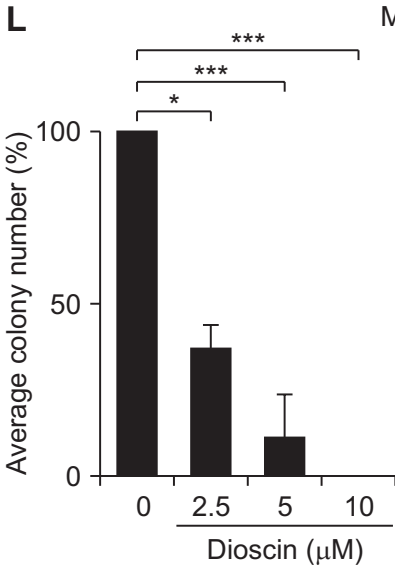

MCF-7

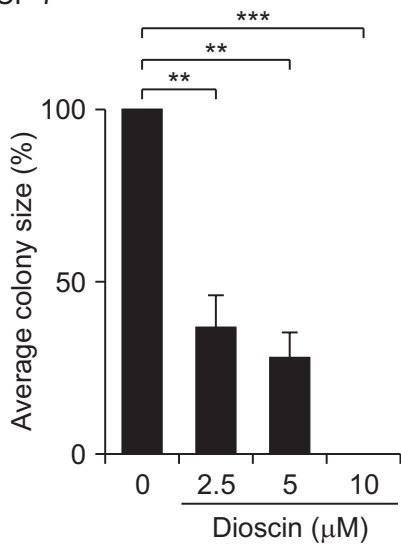

Figure 2. Continued.

hour at room temperature, and then with primary antibodies diluted $(1: 200$ to $1: 1,000)$ in 5\% BSA in TBS-T overnight at $4^{\circ} \mathrm{C}$. Next, the membranes were washed four times $(3 \mathrm{~min}$ utes each) with TBS-T. After washing, the membranes were incubated with anti-rabbit/anti-mouse secondary antibody $(1: 1,000)$ for one hour at room temperature and the reactions were detected using an Advanced Electrochemiluminescence
Western Blot Detection Kit (Amersham, Uppsala, Sweden). The intensities of the protein bands were measured by ImageJ software.

\section{Statistical analysis}

The data are presented as the mean \pm SD for the indicated number of independently performed experiments. Statistical 
analysis was performed by Student's $t$-test for comparison between two groups or one-way ANOVA for comparison between more than two groups. $P<0.05$ was considered to indicate a statistically significant difference. Statistical calculations were performed using SPSS for Windows version 18.0 (SPSS, Chicago, IL, USA).

\section{RESULTS}

\section{DS inhibits MDA-MB-231 and MCF-7 cell proliferation}

The inhibitory effects of DS on cell proliferation were assessed by treating MDA-MB-231 and MCF-7 cells with 0 to $100 \mu \mathrm{M}$ of DS for 24 to 72 hours. The $I_{50}$ values of $D S$ in MDA-MB-231 cells after 24- and 72-hour exposures was $33.55 \mu \mathrm{M}$ and $3.23 \mu \mathrm{M}$, respectively, and the $\mathrm{IC}_{50}$ of DS in MCF-7 cells after 24- and 72-hour exposures was 11.03 $\mu \mathrm{M}$ and $2.50 \mu \mathrm{M}$, respectively (Fig. 1B and $1 \mathrm{C}$ ). The results of this study showed that MDA-MB-231 and MCF-7 cells showed significant sensitivity to the DS treatment concentrations over time. Therefore, further analyses of the biological activities of DS were conducted following treatment at $10 \mu \mathrm{M}$ or less in breast cancer cells.

\section{DS inhibits the migration, invasion, and colony formation of MDA-MB-231 and MCF-7 cells}

For cellular migration analysis, scratches were made to create a gap in the cell monolayer, and a wound-healing assay was performed in different DS treatment conditions. Migration was observed for 24 hours (Fig. 2A and 2B). The change in the area after 24 hours of exposure was compared to the initial wound area in different DS treatment conditions and quantified (Fig. 2C and 2D). The relative gap area was $30.92 \%$ and $101.18 \%$ for MDA-MB-231 cells treated with 0

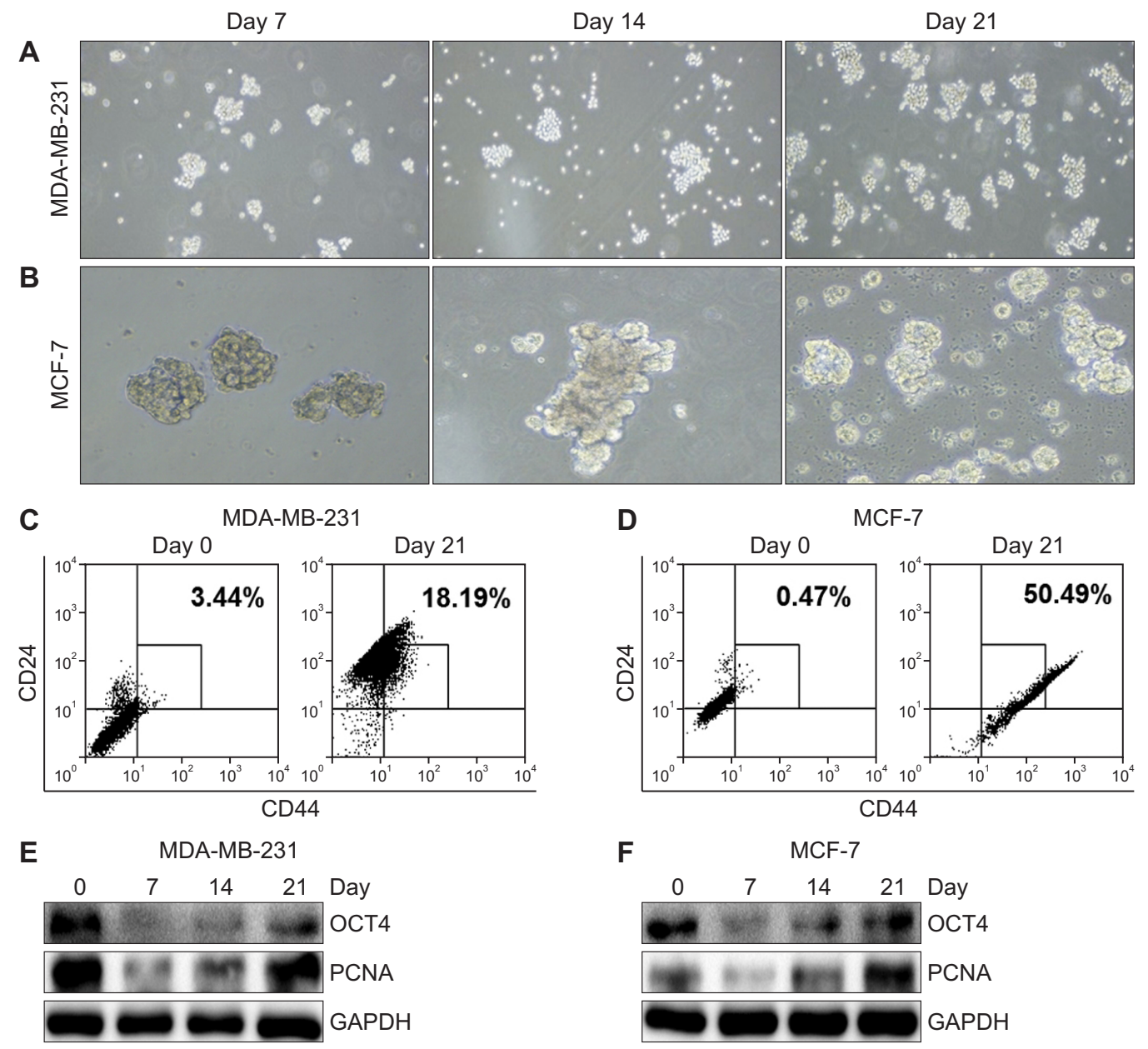

Figure 3. Identification of the characteristics of breast cancer stem-like cells induced to differentiate. (A, B) To establish mammospheres, corresponding cells were seeded in Ultra-Low six-well plates using cancer stem cells culture media for 21 days. Magnification, $\times 100$. (C, D) CD24 ${ }^{\text {low }}$ $\mathrm{CD} 44^{+}$population analysis was performed on day 0 and day 21 of differentiation induction. Representative flow cytometry dot plots of CD24 and CD44 expression of breast cancer stem-like cells. The square indicates the distribution of the CD24 ${ }^{\text {low }} / C D 44^{+}$cell subpopulation. (E, F) Representative blots showing the expression levels of OCT4 and proliferation cell nuclear antigen (PCNA) measured by Western blotting assays. Glyceraldehyde 3-phosphate dehydrogenase (GAPDH) was used as an internal control. 
$\mu \mathrm{M}$ and $10 \mu \mathrm{M}$ DS, respectively. For MCF-7 cells, the relative gap area in cells treated with $0 \mu \mathrm{M}$ and $10 \mu \mathrm{M}$ DS was $45.78 \%$ and $100.13 \%$, respectively, showing that DS treatment significantly reduced migration. In addition, migrative and invasiveness of these cells were measured 48 hours after treatment of DS in Boyden's chamber assay (Fig. 2E and $2 \mathrm{~F})$. Similar to the wound-healing assay results, $5 \mu \mathrm{M}$ and 10 $\mu \mathrm{M}$ DS treatment significantly inhibited the invasion of MDAMB-231 cells by $91.46 \%$ and $99.24 \%$, respectively, compared to the controls. In MCF-7 cells, cell invasion was inhibited by $94.80 \%$ and $98.93 \%$ by treatment with $5 \mu \mathrm{M}$ and $10 \mu \mathrm{M} \mathrm{DS}$, respectively (Fig. $2 \mathrm{G}$ and $2 \mathrm{H}$ ). To assess the inhibitory effects of DS on colony formation, MDA-MB-231 and MCF-7 cells were treated with DS for 24 hours at varying concentrations, and then cultured for 14 days (Fig. $2 \mathrm{I}$ and $2 \mathrm{~J}$ ). The mean colony number and size of the MDA-MB-231 and MCF-7 cells indicated that DS significantly inhibited colony formation in a concentration-dependent manner (Fig. 2K and 2L).

\section{The characteristics of MDA-MB-231 and MCF-7 cells differentiated into BCSCs}

The anti-cancer activity of DS in BCSCs derived from MDAMB-231 and MCF-7 cells was assessed. After culturing in differentiation medium for three weeks, mammosphere formation was observed in both the MDA-MB-231 and MCF-7 cells (Fig. $3 \mathrm{~A}$ and $3 \mathrm{~B}$ ). The CD24 ${ }^{\text {low }} / \mathrm{CD} 44^{+}$phenotype, which is a differentiation characteristic of BCSCs, was analyzed using FACS. After differentiated into BCSCs, the CD24 ${ }^{\text {low }} / \mathrm{CD} 44^{+}$ population increased from $3.44 \%$ to $18.19 \%$ and from $0.47 \%$ to $50.49 \%$ in MDA-MB-231 and MCF-7 cells, respectively (Fig. 3C and 3D). OCT4, a stem cell marker, and PCNA, which is expressed during cell proliferation, were highly expressed in the cancer cells. However, the expression levels rapidly decreased on day 7 and increased again until day 21 of differentiation induction in BCSCs derived from both MDAMB-231 and MCF-7 cells (Fig. 3E and 3F).

\section{DS inhibits mammosphere formation in MDA- MB-231 and MCF-7 cells}

In order to assess whether DS was able to inhibit mammo-

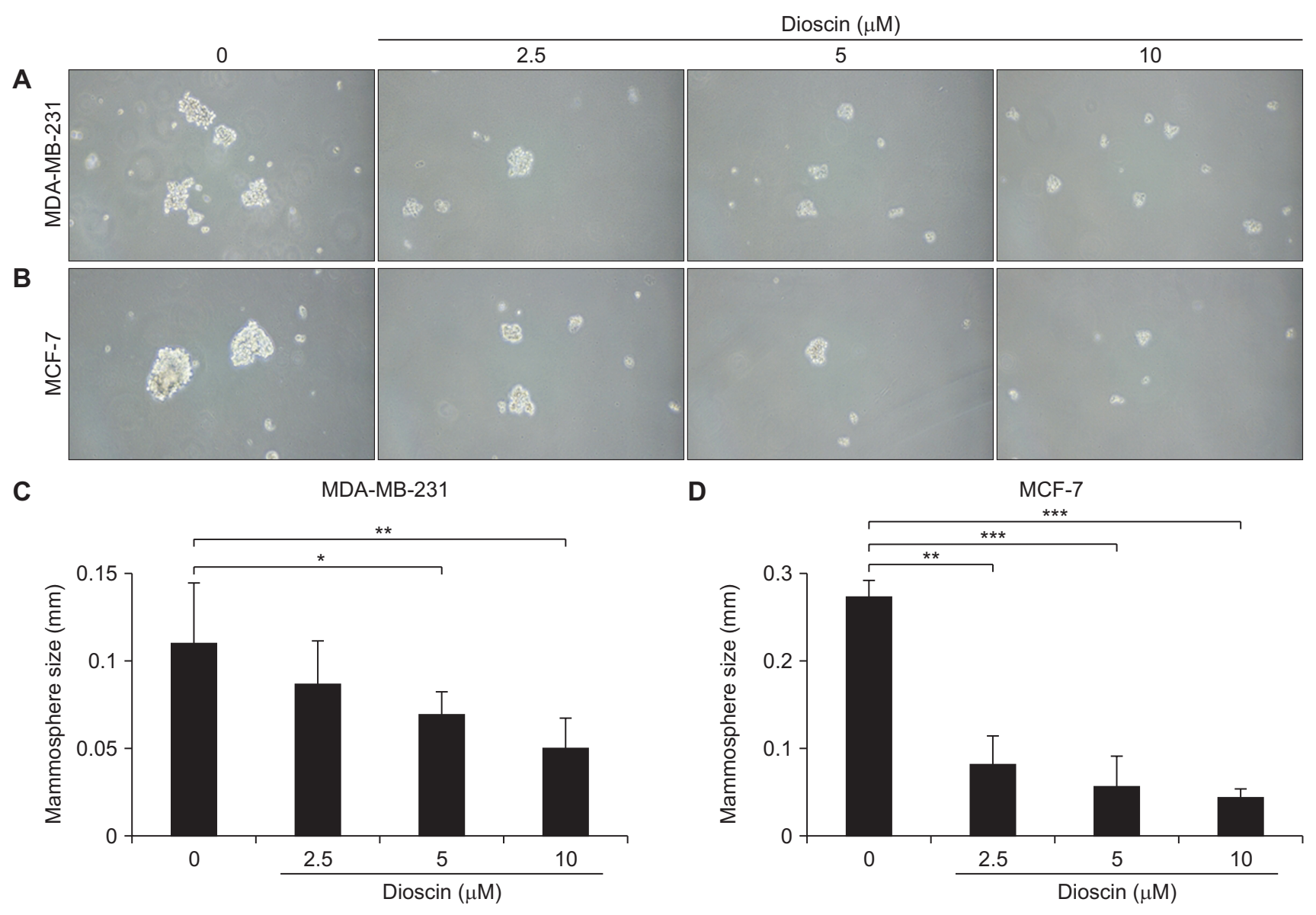

Figure 4. Effect of dioscin on the mammosphere-forming ability of breast cancer stem-like cells. (A, B) Effect of dioscin on the formation of mammospheres derived from human breast cancer cells. Magnification, $\times 100$. (C, D) Quantitative analysis of the mammosphere size. The results shown represent the mean $\pm \mathrm{SD} ;{ }^{*} P<0.05,{ }^{* *} P<0.01$, ${ }^{* \star *} P<0.001$ compared to the controls. 
sphere formation, the cells were treated with different concentrations of DS for 48 hours, after which the DS-containing medium was removed. During the 3 weeks of differentiation to BCSCs, the medium was replaced with fresh one twice per week (Fig. 4A and 4B). In the $10 \mu \mathrm{M}$ DS-treated group, the size of the mammospheres derived from MDA-MB-231 and MCF-7 cells was significantly decreased by $54.73 \%$ and $84.20 \%$, respectively, compared to the control group (Fig. 4C and 4D).

\section{DS induces cell cycle arrest in breast cancer stem-like cells}

After confirming the inhibitory effects of DS on the growth of
MDA-MB-231 and MCF-7 cells and mammosphere formation, further experiments were performed to assess whether DS could cause cell cycle arrest. After differentiation into breast cancer stem-like cells, the cells were treated with DS for 24 hours. Then, the cells were stained with PI to quantitatively analyze the DNA content using flow cytometry. DS treatment induced G2/M and G0/G1 cell cycle arrest in breast cancer stem-like cells derived from MDA-MB-231 and MCF7 cells, respectively (Fig. 5A and $5 B$ ). To investigate the molecular events related to cell cycle arrest induced by DS in breast cancer stem-like cells, various proteins regulating the cell cycle were analyzed (Fig. 5C and 5D). DS treatment significantly increased the expression levels of p53 and p21
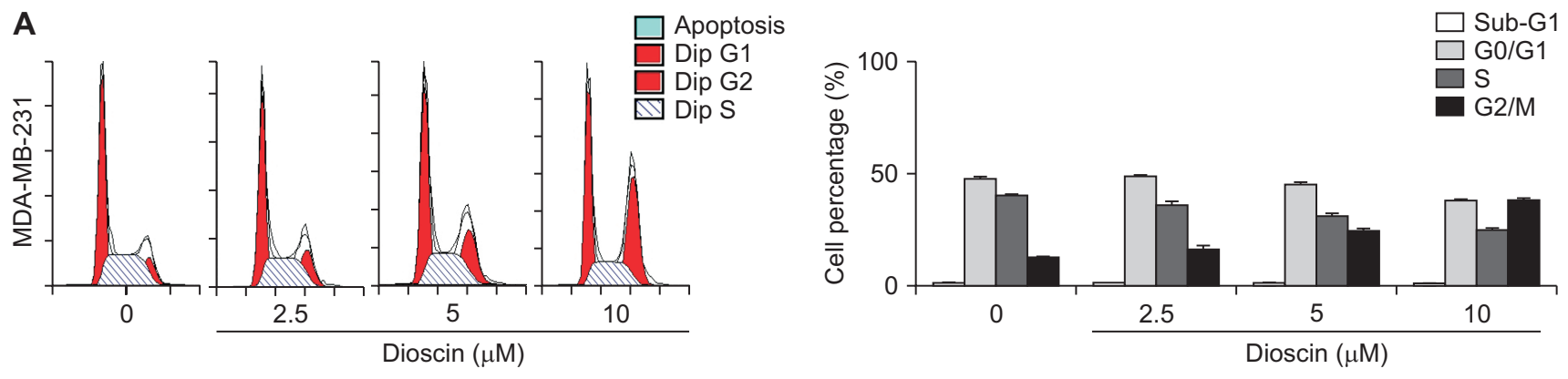

B
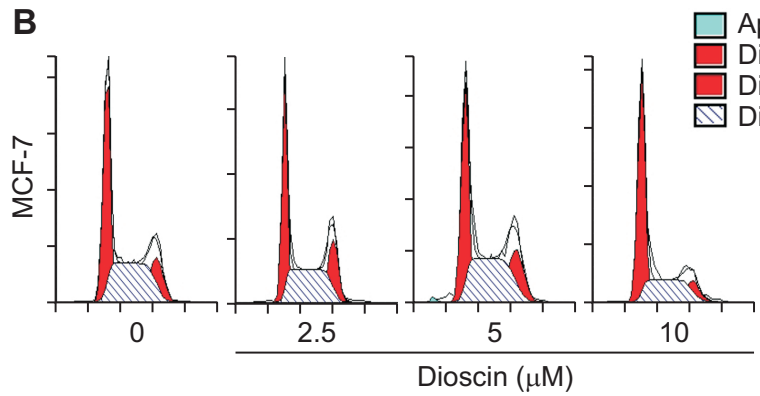

Apoptosis

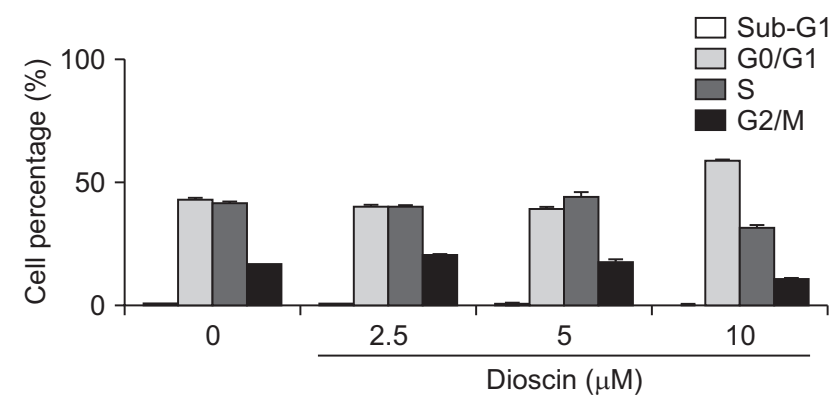

C

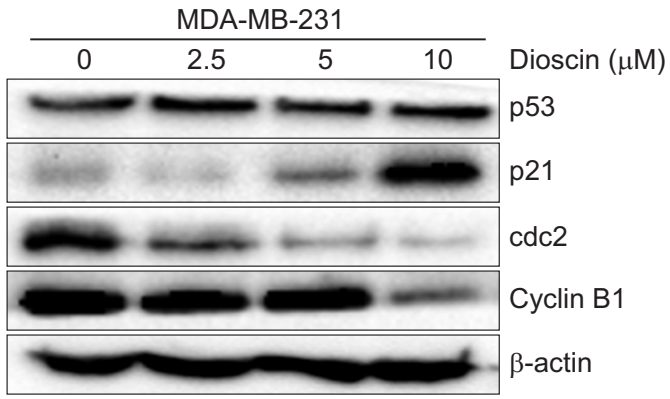

D

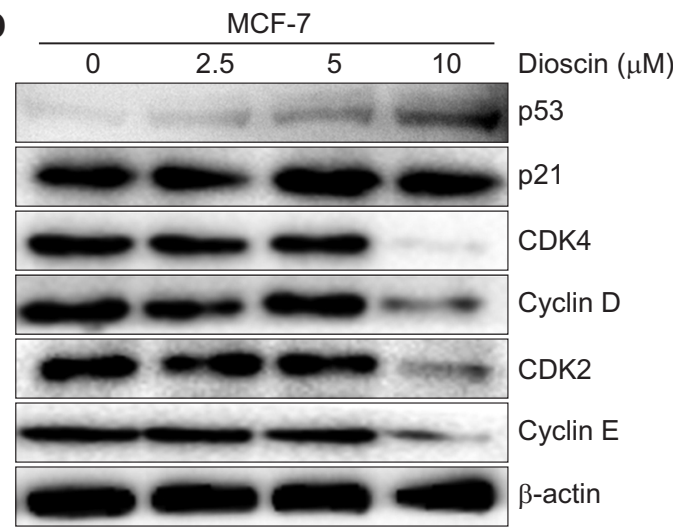

Figure 5. Effect of dioscin on cell cycle distribution and protein expression in breast cancer stem-like cells. (A, B) Representative DNA fluorescence histograms showing the distribution of specific cell populations in sub-G1, G0/G, $\mathrm{S}$, and $\mathrm{G}_{2} / \mathrm{M}$ phases in breast cancer stem-like cells treated with dioscin at $2.5,5$, and $10 \mu \mathrm{M}$ for 24 hours and then subjected to flow cytometry analysis. The bar graphs show the percentage of breast cancer stem-like cells in sub-G1, G0/G, $\mathrm{S}$, and $\mathrm{G}_{2} / \mathrm{M}$ phases. The cells were stained using propidium iodide (PI) and subjected to flow cytometry analysis that collected 10,000 events. (C, D) Representative blots showing the expression levels of p53, p21, cdc2, cyclin B1, CDK4, cyclin D, CDK2, and cyclin E measured by Western blotting assays. MDA-MB-231 and MCF-7-derived breast cancer stem-like cells were treated with dioscin at 2.5, 5, and $10 \mu \mathrm{M}$ for 24 hours. $\beta$-actin was used as an internal control. The data are the mean \pm SD of three independent experiments. 
in MDA-MB-231 and MCF-7-derived breast cancer stemlike cells. However, the expression of cdc2 and cyclin B1 in breast cancer stem-like cells derived from MDA-MB-231 that induced G2/M cell cycle arrest was significantly decreased. In MCF-7-derived breast cancer stem-like cells, the levels of CDK4, cyclin D, CDK2, and cyclin E that induced G0/G1 cell cycle arrest were reduced.

\section{DS inhibits the AKT/mTOR signaling pathway in breast cancer stem-like cells}

AKT/mTOR signaling is one of the active pathways in most cancers, and this pathway plays a variety of physiological roles, including the regulation of cell growth, cycle, and survival. After differentiation into breast cancer stem-like cells for three weeks, the cells were treated with DS for 24 hours, and p38 mitogen-activated protein kinase (MAPK) and AKT/
mTOR signaling was assessed. In breast cancer stem-like cells derived from MDA-MB-231 and MCF-7 cells, DS increased p-p38 MAPK expression and decreased p-AKT and p-mTOR expression in a concentration-dependent manner (Fig. 6A and 6B). Moreover, LY-294002, an inhibitor of AKT, co-treated with DS significantly inhibited the activation of p-AKT (Fig. 6C and 6D, and quantified in Fig. 6E and 6F).

\section{DISCUSSION}

As the incidence of breast cancer is increasing worldwide, research for effective treatments of BCSCs is also increasing. Although BCSCs represent a minor population of breast cancer cells, they are very aggressive and hence account for high lethality. General chemotherapy has side effects, including drug resistance, that cause toxicity to normal cells [27].
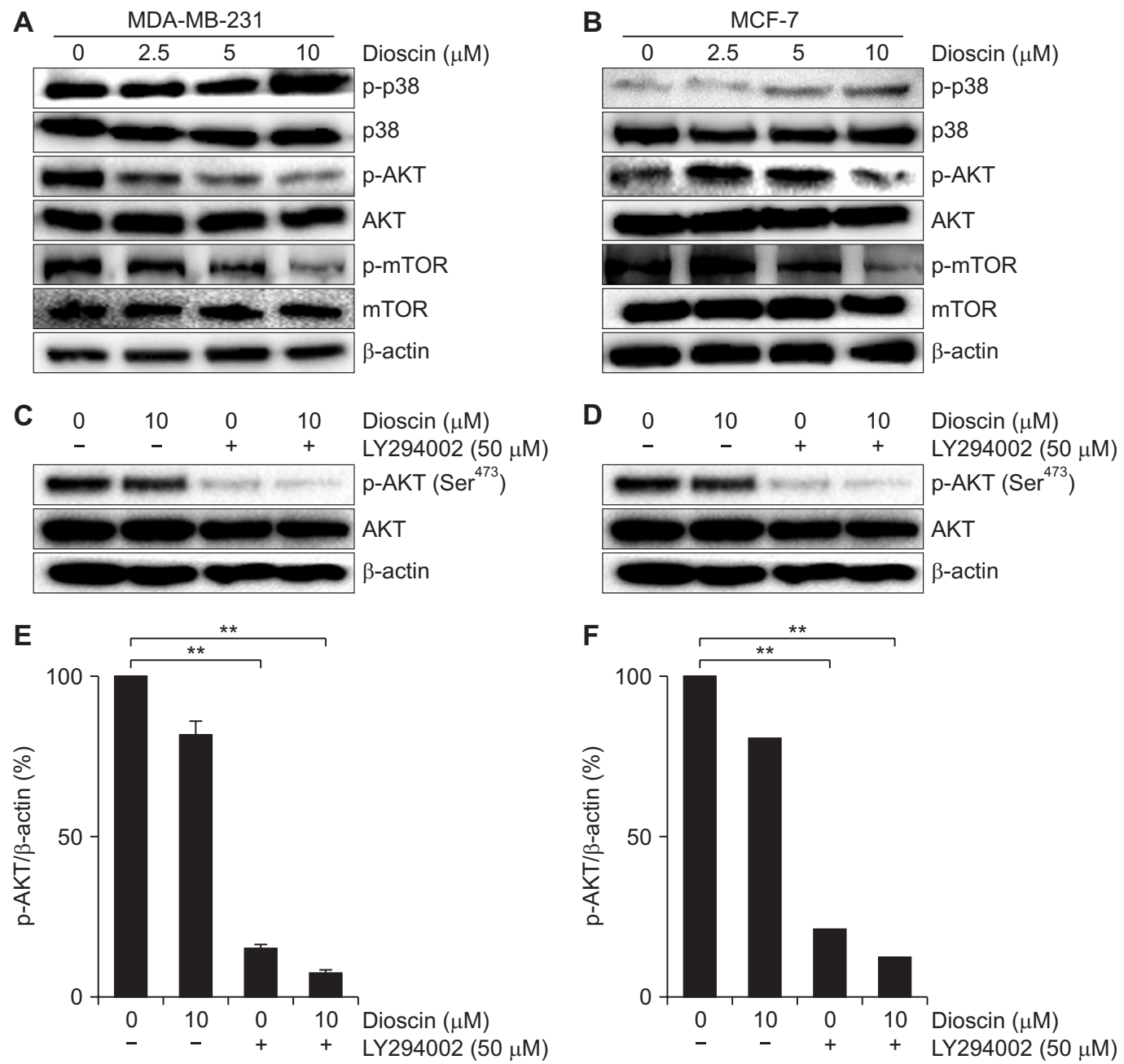

Figure 6. Effect of dioscin on the phosphorylation of p38 mitogen-activated protein kinase (MAPK), AKT, and mTOR in breast cancer stemlike cells. (A, B) Representative blots showing the expression levels of p-p38, p38, p-Akt, Akt, p-mTOR, and mTOR in breast cancer stem-like cells treated with dioscin at 2.5, 5, or $10 \mu \mathrm{M}$ for 24 hours. (C, D) The cells were treated with dioscin in combination with the AKT inhibitor LY294002, and the levels of $\mathrm{p}$-AKT were detected by Western blotting. $\beta$-actin was used as an internal control. (E, F) Bar graphs showing the ratio of $p$-AKT/ $\beta$-actin. The values indicate the mean \pm SD of triplicate tests. ${ }^{*} P<0.05$ and ${ }^{* *} P<0.01$ compared to the control. 
Therefore, there is an emerging interest in treatments using natural products.

This study was the first one to show the anti-cancer activity of DS in breast cancer stem-like cells. MCF-7 cells were more sensitive to the cytotoxic effects of DS treatment compared to MDA-MB-231 cells. In contrast, Aumsuwan et al. [28] reported that MDA-MB-231 cells were more sensitive to DS isolated from wild yam (Dioscorea villosa) root extract. Our present study revealed that DS inhibited the migration, invasion, and colony formation of MDA-MB-231 and MCF-7 cells. Similar to our findings, several studies have also reported the cytotoxic effect of DS in various human malignant cells [29]. Generally, CSCs are defined as cells that initiate tumor growth, have sustained self-renewal, are resistant to drugs, and cause recurrence or metastasis after chemotherapy. They also have migrative, invasive, and colony forming capabilities. The CD24 $4^{\text {low }} / C D 44^{+}$phenotype has been described as a tumorigenic population of BCSCs and is involved in multiple drug resistance mechanisms [30,31]. Another characteristic used to identify BCSCs is the ability to grow under anchorage-independent spheres [32,33]. After inducing mammosphere formation, the CD24 $4^{\text {low }} / C D 44^{+}$phenotype was quantified, and the $\mathrm{CD} 24^{\text {low }} / \mathrm{CD} 44^{+}$population, a specific marker of breast cancer stem-like cells, increased compared to the pre-differentiation population. However, DS treatment inhibited mammosphere formation in the present study.

The increased expression of OCT4, which is an undifferentiated stem cell marker, in CSCs has been reported to mediate the activation of growth factors, and promote cellular proliferation and metastasis in various types of malignancies [34]. The high proliferation activity is one of the notable characteristics of CSCs. PCNA is recognized as a useful indicator of the proliferation of tumor cells, which is closely related to the cell cycles [35]. In this study, the differentiation of MDA-MB-231 and MCF-7 cells into breast cancer stemlike cells led to a sharp decrease in the expression of OCT4 at the beginning of differentiation, followed by elevated OCT4 expression with increased differentiation induction time. Similarly, PCNA expression was also enhanced with increased differentiation induction time.

Cellular proliferation is primarily regulated by the control of the cell cycle and consists of four distinct sequential steps (G0/G1, S, G2, and M) [36]. In eukaryotes, the cell cycle is regulated by cyclins and CDKs. Cyclin D and CDK4 regulate the G0/G1 phase, and cyclin B1 and cdc2 proteins regulate the G2/M phase [37]. In this study, DS caused G2/M phase and G0/G1 phase arrest in MDA-MB-231 and MCF7 cells, respectively, in a concentration-dependent manner. Furthermore, the major regulatory factors of the cell cycle checkpoints, including cdc2, CDK4, CDK2, cyclin B1, cyclin $\mathrm{D}$, and cyclin $\mathrm{E}$ were assessed. The p53 tumor suppressor gene plays an important role in mediating cell responses by regulating various genes involved in apoptosis, cell cycle arrest, and DNA repair [38]. Moreover, p53 induces the tran- scription of various genes including the CDK inhibitor p21, which is an important negative cell cycle regulator. The cyclin-CDK complex controls the cell cycle, inducing cell cycle progression. The induction of $\mathrm{p} 21$ leads to inhibition of the cyclin-CDK complex and consequently induces cell cycle arrest. It was observed that the expression levels of p53 and p21 were significantly increased in MDA-MB-231 and MCF7 cells treated with DS. The cdc2-cyclin B1 complex plays a pivotal role in regulating $\mathrm{G} 2 / \mathrm{M}$ phase transition and mitosis [39]. In DS-treated MDA-MB-231 cells, the cdc2 and cyclin B1 expression levels were significantly decreased, indicating that DS induced G2/M phase arrest in MDA-MB-231 cells. In contrast, the cyclin D, cyclin E, CDK4, and CDK2 expression levels were decreased in a concentration-dependent manner, leading to G0/G1 cell cycle arrest in the MCF-7 cells treated with DS.

In this study, DS inhibited the activity of AKT and mTOR by inducing p38 MAPK expression. p38 MAPK is an important stress kinase involved in the regulation of inflammation, cell growth and differentiation, the cell cycle, and cell death [40]. The PI3K/AKT/mTOR pathway also plays an important regulatory role in proliferation, migration, angiogenesis, and cell survival. This is an important pathway that may serve as a possible treatment target for breast cancer [41]. In this study, DS increased the expression of p-p38 MAPK and decreased the expression level of $p-A K T$. This led to the downregulation of p-mTOR, thereby inhibiting the AKT/mTOR signaling pathway in human breast cancer stem-like cells.

In conclusion, our results show that DS treatment inhibits the mammosphere formation of breast cancer stem-like cells and induces G2/M and G0/G1 cell cycle arrest in MDAMB-231 and MCF-7-derived stem-like cells, respectively. Moreover, DS inhibits cell proliferation by inducing p38 MAPK and regulating the AKT/mTOR signaling pathway. These findings suggest that DS may serve as a potential therapeutic candidate for the treatment of human BCSCs.

\section{ACKNOWLEDGIMENTS}

This work was supported by the Basic Science Research program through the National Research Foundation of Korea (NRF) funded by the Ministry of Education (grant number 2017R1D1A3B03034506).

\section{CONFLICTS OF INTEREST}

No potential conflicts of interest were disclosed.

\section{ORCID}

Chae Won Ock, https://orcid.org/0000-0002-0207-106X

Gi Dae Kim, https://orcid.org/0000-0002-8149-5361 


\section{REFERENCES}

1. Bray F, Ferlay J, Soerjomataram I, Siegel RL, Torre LA, Jemal A. Global cancer statistics 2018: GLOBOCAN estimates of incidence and mortality worldwide for 36 cancers in 185 countries. CA Cancer J Clin 2018;68:394-424.

2. Felipe Lima J, Nofech-Mozes S, Bayani J, Bartlett JM. EMT in breast carcinoma-a review. J Clin Med 2016;5:65.

3. La Belle A, Khatib J, Schiemann WP, Vinayak S. Role of platinum in early-stage triple-negative breast cancer. Curr Treat Options Oncol 2017;18:68.

4. Park SY, Choi JH, Nam JS. Targeting cancer stem cells in triplenegative breast cancer. Cancers (Basel) 2019;11:965.

5. Frank NY, Schatton T, Frank MH. The therapeutic promise of the cancer stem cell concept. J Clin Invest 2010;120:41-50.

6. Wu HJ, Chu PY. Role of cancer stem cells in cholangiocarcinoma and therapeutic implications. Int J Mol Sci 2019;20:4154.

7. Michor F, Polyak K. The origins and implications of intratumor heterogeneity. Cancer Prev Res (Phila) 2010;3:1361-4.

8. Idowu MO, Kmieciak M, Dumur C, Burton RS, Grimes MM, Powers CN, et al. CD44(+)/CD24(-/low) cancer stem/progenitor cells are more abundant in triple-negative invasive breast carcinoma phenotype and are associated with poor outcome. Hum Pathol 2012;43:364-73.

9. Dandawate P, Padhye S, Ahmad A, Sarkar FH. Novel strategies targeting cancer stem cells through phytochemicals and their analogs. Drug Deliv Transl Res 2013;3:165-82.

10. Porta C, Paglino C, Mosca A. Targeting PI3K/Akt/mTOR signaling in cancer. Front Oncol 2014;4:64.

11. Steelman LS, Abrams SL, Whelan J, Bertrand FE, Ludwig DE, Bäsecke J, et al. Contributions of the Raf/MEK/ERK, PI3K/PTEN/ Akt/mTOR and Jak/STAT pathways to leukemia. Leukemia 2008;22:686-707.

12. Xia $P, X u X Y$. PI3K/Akt/mTOR signaling pathway in cancer stem cells: from basic research to clinical application. Am J Cancer Res 2015;5:1602-9.

13. Sridharan S, Howard CM, Tilley AMC, Subramaniyan B, Tiwari AK, Ruch RJ, et al. Novel and alternative targets against breast cancer stemness to combat chemoresistance. Front Oncol 2019;9:1003.

14. Singh JK, Farnie G, Bundred NJ, Simões BM, Shergill A, Landberg G, et al. Targeting CXCR1/2 significantly reduces breast cancer stem cell activity and increases the efficacy of inhibiting HER2 via HER2-dependent and -independent mechanisms. Clin Cancer Res 2013;19:643-56.

15. Hernandez-Aya LF, Gonzalez-Angulo AM. Targeting the phosphatidylinositol 3-kinase signaling pathway in breast cancer. Oncologist 2011;16:404-14.

16. Thomasset SC, Berry DP, Garcea G, Marczylo T, Steward WP, Gescher AJ. Dietary polyphenolic phytochemicals--promising cancer chemopreventive agents in humans? A review of their clinical properties. Int J Cancer 2007;120:451-8.

17. Güçlü-Ustündağ $O$, Mazza G. Saponins: properties, applications and processing. Crit Rev Food Sci Nutr 2007;47:231-58.
18. Pan CH, Tsai CH, Liu FC, Fan MJ, Sheu MJ, Hsieh WT, et al. Influence of different particle processing on hypocholesterolemic and antiatherogenic activities of yam (Dioscorea pseudojaponica) in cholesterol-fed rabbit model. J Sci Food Agric 2013;93:127883.

19. Xu LN, Yin LH, Jin Y, Qi Y, Han X, Xu YW, et al. Effect and possible mechanisms of dioscin on ameliorating metabolic glycolipid metabolic disorder in type-2-diabetes. Phytomedicine 2020;67:153139.

20. Yang Q, Wang C, Jin Y, Ma X, Xie T, Wang J, et al. Disocin prevents postmenopausal atherosclerosis in ovariectomized LDLR-/- mice through a PGC-1 $\alpha / E R \alpha$ pathway leading to promotion of autophagy and inhibition of oxidative stress, inflammation and apoptosis. Pharmacol Res 2019;148:104414.

21. Xu XH, Li T, Fong CM, Chen X, Chen XJ, Wang YT, et al. Saponins from chinese medicines as anticancer agents. Molecules 2016;21:1326.

22. Tao X, Yin L, Xu L, Peng J. Dioscin: a diverse acting natural compound with therapeutic potential in metabolic diseases, cancer, inflammation and infections. Pharmacol Res 2018;137:259-69.

23. Chen J, Li HM, Zhang XN, Xiong CM, Ruan JL. Dioscin-induced apoptosis of human LNCaP prostate carcinoma cells through activation of caspase-3 and modulation of Bcl-2 protein family. J Huazhong Univ Sci Technolog Med Sci 2014;34:125-30.

24. Lim WC, Kim H, Kim YJ, Choi KC, Lee IH, Lee KH, et al. Dioscin suppresses TGF- $\beta 1$-induced epithelial-mesenchymal transition and suppresses A549 lung cancer migration and invasion. Bioorg Med Chem Lett 2017;27:3342-8.

25. Lombardo Y, de Giorgio A, Coombes CR, Stebbing J, Castellano L. Mammosphere formation assay from human breast cancer tissues and cell lines. J Vis Exp 2015;(97):52671.

26. Jafari SM, Joshaghani HR, Panjehpour M, Aghaei M, Zargar Balajam N. Apoptosis and cell cycle regulatory effects of adenosine by modulation of GLI-1 and ERK1/2 pathways in CD44+ and CD24- breast cancer stem cells. Cell Prolif 2017;50:e12345.

27. Kern KM, Schroeder JR. Comparison of cantharidin toxicity in breast cancer cells to two common chemotherapeutics. Int J Breast Cancer 2014;2014:423059.

28. Aumsuwan P, Khan SI, Khan IA, Ali Z, Avula B, Walker LA, et al. The anticancer potential of steroidal saponin, dioscin, isolated from wild yam (Dioscorea villosa) root extract in invasive human breast cancer cell line MDA-MB-231 in vitro. Arch Biochem Biophys 2016;591:98-110.

29. Wang Y, He QY, Chiu JF. Dioscin induced activation of p38 MAPK and JNK via mitochondrial pathway in HL-60 cell line. Eur J Pharmacol 2014;735:52-8.

30. Al-Hajj M, Wicha MS, Benito-Hernandez A, Morrison SJ, Clarke MF. Prospective identification of tumorigenic breast cancer cells. Proc Natl Acad Sci USA 2003;100:3983-8.

31. Phillips TM, McBride WH, Pajonk F. The response of CD24(-/ low)/CD44+ breast cancer-initiating cells to radiation. J Natl Cancer Inst 2006;98:1777-85. 
32. Nobili S, Lapucci A, Landini I, Coronnello M, Roviello G, Mini E. Role of ATP-binding cassette transporters in cancer initiation and progression. Semin Cancer Biol 2020;60:72-95.

33. Jordan CT, Guzman ML, Noble M. Cancer stem cells. N Engl J Med 2006;355:1253-61.

34. van Schaijik B, Davis PF, Wickremesekera AC, Tan ST, Itinteang T. Subcellular localisation of the stem cell markers OCT4, SOX2, NANOG, KLF4 and c-MYC in cancer: a review. J Clin Pathol 2018;71:88-91.

35. Wang SC. PCNA: a silent housekeeper or a potential therapeutic target? Trends Pharmacol Sci 2014;35:178-86.

36. Hengartner MO. The biochemistry of apoptosis. Nature 2000;407:770-6.

37. Cho HJ, Oh YJ, Han SH, Chung HJ, Kim CH, Lee NS, et al. Cdk1 protein-mediated phosphorylation of receptor-associated protein 80 (RAP80) serine 677 modulates DNA damage-induced G2/M checkpoint and cell survival. J Biol Chem 2013;288:376876.

38. Harris SL, Levine AJ. The p53 pathway: positive and negative feedback loops. Oncogene 2005;24:2899-908.

39. Vermeulen K, Van Bockstaele DR, Berneman ZN. The cell cycle: a review of regulation, deregulation and therapeutic targets in cancer. Cell Prolif 2003;36:131-49.

40. Brancho D, Ventura JJ, Jaeschke A, Doran B, Flavell RA, Davis RJ. Role of MLK3 in the regulation of mitogen-activated protein kinase signaling cascades. Mol Cell Biol 2005;25:3670-81.

41. Khan MA, Jain VK, Rizwanullah M, Ahmad J, Jain K. PI3K/ AKT/mTOR pathway inhibitors in triple-negative breast cancer: a review on drug discovery and future challenges. Drug Discov Today 2019;24:2181-91. 